\title{
EDITORIAL
}

\section{Pharmacy student perspectives on learning in and from a global pandemic}

\author{
Yannee Liu (iD), Jessica Kludass (D), Vivienne Mak \\ Faculty of Pharmacy and Pharmaceutical Sciences, Monash University, Australia
}

\author{
Correspondence \\ Vivienne Mak \\ Faculty of Pharmacy and \\ Pharmaceutical Sciences \\ Monash University \\ 381 Royal Parade \\ Parkville \\ Victoria 3052 \\ Australia \\ vivienne.mak@monash.edu
}

\begin{abstract}
The COVID-19 pandemic has transformed the way pharmacy students experience education. Some of these transformations may persist long after the disease abates. In normal circumstances, incoming pharmacy students would be enjoying on-campus university life and/or professional instruction for the very first time. Final year students would be focused on making the practice transition needed for entry to practice. Pandemic-related modifications have changed both of these experiences. The following is a commentary by two pharmacy students reflecting on this - what has been missed, what has been learned, what has been contributed, and what (we hope) happens next.
\end{abstract}

\section{Reflections of a first-year pharmacy student}

2020 has been a challenging year in all of our lives. Nevertheless, it proved to be the year where I learnt the most valuable life lessons. I have learnt to be openminded to change, adaptable to new practices, and use reflection to inform my self-care. Above all, through the focus on skills development in the course, I am learning to be a kinder and more empathetic person.

Like many first-year university students, I was both excited and anxious for this new chapter of my life. I envisioned immersing myself at the university campus by signing up for clubs, competitions, volunteer and leadership opportunities, and events. I imagined forming diverse new friendships. Prior to COVID-19, a normal on-campus week for a full-time first-year pharmacy student consisted of eight hours of self-directed study of preparatory materials, eight hours of interactive lectures and eight hours of application-based small group workshops. We would also have one hour of skills coaching every few weeks to reflect on and develop our professional skills (e.g. problem solving, oral communication, written communication, empathy, reflective practice, integrity, teamwork and inquiry) (Lyons, Christopoulos, \& Brock, 2020).

The pharmacy course has maintained this structure but has converted it to an online model. We still do the self-directed study and then, interactive lectures are conducted online - synchronously and asynchronously - to further explore fundamental biology, chemistry, and professional practice concepts through real-life scenarios. In workshops conducted over Zoom, we work in designated teams in 'breakout rooms' to apply concepts from medicinal chemistry, pharmacology, and pharmacokinetics to case study scenarios. We still meet with our coaches every few weeks, but these sessions are also held via Zoom. Our instructors also hold a combined weekly online (optional) webinar to answer our questions and check in on our well-being. 
For me, the most challenging aspects of online learning have been staying organised, motivated and focused on the bigger goals. However, I have found self-reflection to be greatly helpful, allowing for clarity and creating a positive environment. Reflective practice is an integral aspect for healthcare professionals to improve healthcare practices and ensure quality patient outcomes. As a pharmacist-in-training, I've learned the great value of taking time in my day to reflect; whether it is about work, studies or personal matters.

In addition, I have not compromised my original goals of getting involved. My university experience has been greatly enriched by serving as a student ambassador, getting involved in marketing events, volunteering with the student union and United Nations Youth Victoria, as well as mentoring students from disadvantaged backgrounds through the university mentoring programme. One of the real highlights was participating in an international 'Influenza Hackathon' virtual competition aimed at improving vaccination uptake in the Asia-Pacific region. It was a rewarding inter-professional experience that opened my eyes to learning about infectious diseases, healthcare policies, and advocacy. As a result of this, I am now volunteering with the Australian Immunisation Coalition to implement innovative solutions to increase influenza vaccination uptake in Australia.

Above all, the most valuable lesson I have learnt is to be kind and empathetic, and being grateful for the little things in life. Lockdown and restrictions have changed the way we interact socially. By being open-minded and adaptable to change, I have found new ways to connect. I really look forward to our weekly webinars and coffee chats. It is a great way to communicate with peers and instructors. We share stories from exciting encounters while working in a community pharmacy to funny food and pet stories. The sessions are always filled with laughter. These would, perhaps, not be feasible or prioritised if we were on campus. They remind me that patients deserve our support and positivity, too.

Overall, by becoming more adaptable, resilient, and empathetic, I have been able to overcome academic challenges and learn from the opportunities offered to me as a first-year pharmacy student in 2020.

\section{Reflections of a final-year pharmacy student}

As a final-year pharmacy student, I was undertaking project and clinical placements during the COVID-19 pandemic. At first, when the disease was distant to us, it was interesting to participate in seminar discussions about the virus and potential treatments held at my placement site. As more people became ill closer to home, I began to have concerns about whether my placements would continue as planned but even more so, for my own safety. By being embedded in a healthcare environment, however, I experienced best practices for safety and had an interesting vantage point for seeing how pharmacist roles were changing as a result. What I observed was that pharmacists were seen as active contributors to the multidisciplinary team, taking on enhanced roles like managing drug shortages, developing treatment protocols and recruiting participants for clinical trials (Elbeddini et al., 2020). I even experienced these new responsibilities myself as I was adopted into the medical team as a care extender (Dooley, 2020).

Prior to COVID-19, placements were strongly focussed around observing a preceptor complete clinical tasks (i.e. conducting a best possible medication history, medication reconciliation, discharge counselling and medication interventions), then, as a student, performing these tasks under direct supervision of the preceptor who provides immediate feedback. During the pandemic, trained students were relied upon to complete additional duties. Rostered to the Intensive Care Unit (ICU) comprising of COVID-19 positive and suspected patients, I had an extended scope of practice during my placement to streamline the workflow of health professionals and reduce the wastage of personal protective equipment (PPE). I was trained in the correct application and removal of PPE, how to order non-imprest medications and how to deliver medications to the individual isolation rooms in the ICU. These opportunities and responsibilities would not have been available to me if not for the pandemic.

A day on placement started with me arriving at $0700 \mathrm{H}$, donning PPE, checking in with the night pharmacist, liaising with nurses in individual isolation rooms to determine patient medication requirements and assisting in the medication administration process. I then joined the medical round and met with the day pharmacist. During the medical round and periodically throughout the day, I repeated this process.

As a result of my new role in the hospital, and the lack of direct patient interaction due to the risk of spreading the infection, I adapted to working collaboratively within the healthcare team. After training, I was entrusted to order medications without supervision, including stocking 'when required' medications at my own discretion. This allowed me to develop an appreciation for the contribution of every member of the multidisciplinary healthcare team (e.g. working with nurses as PPE monitors.) 
This was a big step up from my previous (introductory) placement activities. Completing advanced experiential placements during the COVID-19 pandemic has been challenging. Still, I have developed the confidence to interact professionally with other members of the healthcare team and be accountable for my contributions to this team. These attributes will serve me well as an intern (i.e. pre-registration) pharmacist next year.

\section{What the future holds}

The COVID-19 pandemic has led to loss of life, loss of employment, and loss of security. It has challenged learners in many ways. But from these distressing experiences also come some positives. Optimism, connection, adaptability, reflection, volunteerism, resilience, courage, teamwork, and responsibility are all hard-earned lessons that will not only help current pharmacy students but future health professionals seeking to improve healthcare. With empathy and kindness, we trust that we will achieve this improvement together with our peers, instructors, practitioners, and patients.

\section{References}

Dooley M. (2020). Thank you on behalf of the JPPR. Journal of Pharmacy Practice and Research, 50(2), 117. https://doi.org/10. 1002/jppr.1654

Elbeddini, A., Prabaharan, T., Almasalkhi, S., \& Tran, C. (2020). Pharmacists and COVID-19. Journal of Pharmaceutical Policy and Practice, 13, 36. https://doi.org/10.1186/s40545-020-00241-3

Lyons, K. M., Christopoulos, A., \& Brock, T. P. (2020). Sustainable Pharmacy Education in the Time of COVID-19. American Journal of Pharmaceutical Education, 84(6), 667-672. https://doi.org/ $\underline{10.5688 / a j p e 8088}$ 